\title{
Raquitismo Hipofosfatêmico: da Clínica à Genética Molecular
}

\section{RESUMO}

O raquitismo hipofosfatêmico dominante ligado ao cromossomo Xé a forma mais comum de raquitismo familial, e caracteriza-se por hipofosfatemia associada a hiperfosfatúria e metabolismo anormal da vitamina D. Existem outras formas de hiperfosfatúrias hereditárias, sugerindo um complexo processo de homeostase do fosfato. Como não está definida qual a lesão básica do distúrbio, torna-se difícil o esclarecimento da fisiopatologia. Recentemente, através da abordagem de clonagem posicional, foi identificado um forte gene candidato, o PEX, que seria o responsável pelo distúrbio. Diversos tipos de mutações no PEX foram encontradas em cerca de 60 famílias. Os recentes avanços genéticos no estudo dessa doença muito têm contribuído para melhorar o entendimento da sua fisiopatologia e do controle do equilíbrio do fosfato. (Ara Bras Endocrinol Metab 2000;44/2: 125-32)

Unitermos: Raquitismo; Hipofosfatemia; Hiperfosfatúria; Gene PEX

\begin{abstract}
X-linked hypophosphatemic rickets is the most common familial form of rickets and is characterized by hypophosphatemia associated to hyperphosphaturia and abnormal 1,25-dihydroxyvitamin D metabolism. There are several other forms of hereditary hyperphosphaturias, which may indicate the complexity of phosphate homeostasis. As the basic damage has not been defined, its physiology comprehension is still unclear. Recently, using the positional cloning method, a strong candidate gene was identified: the PEX gene (Phosphate-regulating gene homologies to Endopeptidases on the X-chromosome), which seems to be the responsible for the disease. Many types of mutations in PEX were found in more than 60 families. The recent genetic advances in the study of this disease have allowed a much better understanding of its physiopathology. (Arq Bras Endocrinol Metab 2000;44/2: 125-32)
\end{abstract}

Keywords: Rickets; Hypophosphatemia; Hyperphosphaturia; PEX gene

\section{REVISÃO HISTÓRICA}

O raquitismo hipofosfatêmico dominante ligado ao X (XLHR ou HYP; MIM 307800) (1) é a forma mais comum de raquitismo hereditário, com uma incidência estimada de 1:20.000 indivíduos (2).

Os primeiros relatos sobre esse raquitismo, na literatura, datam de 1937, quando Albright e col. (3) descreveram vários distúrbios de morfologia e formação óssea associados à resistência ao tratamento com vitamina $\mathrm{D}$.

Winters e col. (4), estudando uma grande família da Carolina do Norte de pacientes com raquitismo resistente à vitamina $\mathrm{D}$, reconhece-
Universidade Federal da Paraiba e Disciplina de Endocrinologia da Universidade Federal de São Paulo, UNIFESP, São Paulo.
Recebido em 28/04/98

Revisado em 06/12/99 Aceito em 17/12/99 
ram que a hipofosfatemia era o marcador mais relacionado com a presença do determinante genético, daí surgiu o termo "raquitismo hipofosfatêmico resistente à vitamina D".

Em 1941, Christiansen (5) descreveu a doença como autossômica dominante porque o fenótipo era dado apenas pelas anormalidades esqueléticas grosseiras. Usando a hipofosfatemia como critério fenotípico, Burnett (2) demonstrou que a doença era ligada ao $\mathrm{X}$, com herança dominante. $\mathrm{O}$ achado de algumas mulheres heterozigotas que mostram pouca ou nenhuma evidência de doença óssea, mas que são hipofosfatêmicas, indica a herança não autossômica.

Desde essas descrições iniciais, muitos casos e famílias de afetados foram descritos, e as características clínicas foram extensamente validadas.

\section{CARACTERISTICAS CLÍNICAS}

A principal característica da doença é uma perda renal inadequada de fosfato, que leva a uma hipofosfatemia com fosfatúria elevada e mineralização óssea defeituosa. Os pacientes apresentam raquitismo e osteomalácia, deformidades em membros inferiores, dores ósseas, baixa estatura, anormalidades dentárias e metabolismo alterado da vitamina $D$.

Em indivíduos normais com hipofosfatemia, ocorrem mudanças no metabolismo da vitamina $\mathrm{D}$ que aumentam os níveis circulantes de calcitriol. Essas mudanças, que visam uma maior retenção de fosfato, não ocorrem no paciente com XLHR.

Existem vários outros distúrbios menos comuns de perda renal hereditária de fosfato. O raquitismo hereditário autossômico dominante (ADHR) tem sido relatado desde 1971 (6), catalogado sob o número 193100 no registro de herança mendeliana no homem (MIM) (1). Econs e McEnery (7) estudaram uma grande família ( 79 pessoas) com 23 afetados, possivelmente compartilhando a mesma mutação. Os pacientes apresentam baixa estatura, dores ósseas, raquitismo e osteomalácia. Os achados mostram que o ADHR apresenta características que não são vistas em outras formas de distúrbios hereditários hipofosfatêmicos, criando dificuldades para o seu diagnóstico. Vários indivíduos apresentaram o início da doença entre as idades de 14-45 anos, caracterizado principalmente por fraqueza, dores ósseas e pseudofraturas, inclusive com níveis séricos de fosfato normais anteriormente ao início da doença. Outros pacientes apresentam a doença na infầncia e não mais demonstram o defeito para perda de fosfato na vida adulta. Essa família mostrou um padrão de herança autossômica dominante. As famílias até então descritas eram pequenas e não caracterizavam adequadamente o fenótipo. Então, o espectro da doença ADHR inclui não apenas a apresentação clássica com o início precoce de raquitismo e hipofosfatemia, como também o início tardio e a resolução do defeito, indicando que o distúrbio da perda de fosfato em alguns indivíduos afetados pode ser compensado por outros fatores hormonais, genéticos ou ambientais.

O raquitismo hereditário hipofosfatêmico com hipercalciúria (HHRH) (MIM 241530) (1,8), descrito recentemente em uma tribo de beduínos, é um distúrbio autossômico com perda renal de fosfato, concentrações elevadas de calcitriol, hipercalciúria e nefrolitíase. Dois possíveis modos de herança foram propostos para essa condição: recessiva, com efeitos aditivos de dois genes, ou dominante, com expressão variável. A doença também tem sido obscrvada em outros grupos étnicos.

Slyper e col. (9) relataram um caso de raquitismo hipofosfatêmico com hipercalciúria no qual os níveis de PTH cram normais apesar da clevação modesta de calcitriol, parecendo um tipo diferente dos já descritos de osteomalácia hipofosfatêmica. Apesar de história familiar de nefrolitíase, não parecia haver doença óssea na família. Infelizmente, a família não cstava disponível para testes.

A doença óssea hipofosfatêmica (HBD) (MIM 146350), descrita por Scriver $(1,10)$, apresenta perda renal de fosfato, com padrão de herança autossômico dominante, diferindo da ADHR pois as crianças não apresentam sinais radiológicos de raquitismo, o que é discutível uma vez que esses sinais radiológicos não são universais no XLHR ou na ADHR, talvez não constituindo uma entidade clínica distinta. Uma das famílias descritas apresentava, inclusive, casos de XLHR.

Essas múltiplas formas de hiperfosfatúria hereditária indicam que o processo de homeostase do fosfato é complexo. Segundo Dennis e col. (11), a existência de um defeito autossômico dominante no transporte renal de fosfato (docnça óssea hipofosfatêmica) sugere que dois mecanismos de conservação do fosfato formaram-se evolutivamente. Tais mecanismos operam em diferentes partes do túbulo renal (pars recta e túbulo contorcido proximal) e apenas um é influenciado pelo PTH.

\section{HIPÓTESES FISIOPATOLÓGICAS}

Muito do nosso entendimento sobre a fisiopatologia do XLHR veio de estudos sobre anormalidades bio- 
químicas renais e ósseas com os modelos animais. Exis tem dois modelos animais descritos para o raquitismo hipofosfatêmico. Ambos têm hiperfosfatúria, defeito na mineralização óssea e retardo de crescimento. O primeiro é chamado Hyp e mimetiza bem as características da doença humana. Outro modelo é chamado Gy (gyro) que apresenta, além da perda renal de fosfato, um comportamento associado a movimentos rotatórios peculiares, anormalidades $\mathrm{cm}$ orelha, surdez e hiperatividade. Há controvérsias sobre alteraçōes no metabolismo da vitamina $D$ neste mutante. O camundongo Hyp surgiu de uma mutação espontânea. A mutação do Gy foi induzida por irradiação.

As diversas formas clínicas de raquitismo hereditário e a existência da osteomalácia hipofosfatêmica oncogênica sugerem que a homeostase do fosfato envolve múltiplos produtos gênicos.

A localização do defcito primário no XLHR é muito dificultada pois não há uma lesão primária definida e nem se conhece o tecido de origem do(s) produto(s) gênico(s) defeituoso(s). Contudo, a clonagem posicional tem se revelado uma estratégia cada vez mais eficiente na localização de vários genes de importância médica c os estudos sobre o gene XLHR usando esse tipo de abordagem permitiram definir um forte gene candidato. Como é freqüientemente observado, quando genes de doenças são identificados pela clonagem posicional, o isolamento do gene não garante o entendimento imediato da fisiopatologia.

\section{PERDA RENAL DE FOSFATO}

Foi demonstrado, no modelo do camundongo Hyp, um fluxo anormal de fosfato através da borda em escova da membrana luminal do túbulo contorcido proximal, c estudos de micropuntura sugeriram que o co-transportador de fosfato $\mathrm{Na}^{+}$-dependente estava prejudicado (12). $\mathrm{O}$ gene para o transportador $\mathrm{Na}$-dependente foi clonado e localizado no cromossomo 5 (13). É improvável, portanto, que um defeito nesse gene seja a lesão primária no XLHR. Usando a técnica da clonagem de expressão, foi identificado o transportador $\mathrm{Na}^{+}$-fosfato tubular do camundongo, cuja análise demostrou uma diminuição na transcrição e tradução do RNAm. Talvez uma menor expressão do mRNA e da protéína do co-transportador no modelo do camundongo Hyp sugira que a mutação do XLHR pode afetar indiretamente o co-transportador $\mathrm{Na}^{+}$-fosfato.

Estudos mais recentes (14) indicam que o Hyp tem intrinsecamente um transporte de fosfato normal no rim, e que essa excreção anormal de fosfato pode ser secundária à presença de um fator humoral.

\section{METABOLISMO DA VITAMINA D}

Quando se considera a fisiopatologia do XLHR, um fator chave a ser observado é a regulação do calcitriol. Nesta doença, os níveis de calcitriol circulantes nào se elevam, apesar da hipofosfatemia. No camundongo Hyp, isto é causado pela ausência do incremento da $1-\alpha$-hidroxilase $c$ pelo metabolismo paradoxalmente elevado pela 24 -hidroxilase mitocondrial. Essa regulação anormal da bioativação da vitamina $D$ foi vista apenas no rim. Alguns experimentos mostraram que o aumento da atividade 24 hidroxilase era decorrente da maior ativação de transcrição do genc da 24-hidroxilase (I5).

$O$ gene da 24-hidroxilase tem sua expressão aumentada no camundongo Hyp. Isto resulta em um aumento do clearance do metabólito ativo da vitamina D - o calcitriol - via a oxidaçào C24, podendo ser responsável pelos níveis inapropriadamente reduzidos do hormônio no camundongo Hyp, e por analogia, no XLHR. O gene da 24-hidroxilase situa-se no cromossomo 20 (16) e é, portanto, improvável que seja o defeito primário no Hyp.

\section{FATOR HUMORAL NO XLHR}

Embora um defeito intrínseco renal scja reconhecidamente um ponto importante na fisiopatologia da doença, ainda não foi demonstrado conclusivamente que seja uma lesão primária. Talvez, à semelhança do que ocorre na osteomalácia oncogênica, um fator humoral cause a anormalidade na regulação da perda de fosfato.

Meyer e col. (17) fizeram uma ligação cirúrgica entre um camundongo Hyp e um normal. O experimento mostrou que um fator fosfatúrico parecia cruzar a união parabiótica do camundongo Hyp para o normal, e fazia surgir os sintomas da hipofosfatemia ligada ao $\mathrm{X}$ no camundongo normal.

Experimentos com transplante cruzado (18) mostraram que um rim de camundongo Hyp transplantado para um receptor normal não transmite o fenótipo XLHR, enquanto que um rim normal transplantado para um camundongo Hyp vai apresentar perda renal de fosfato. Isto foi considerado uma forte evidência para a existência de um fator fosfatúrico circulante no fenótipo Hyp, sugerindo-se o nome "fosfatonina" (19) para este fator.

\section{DEFEITO INTRÍNSECO NO OSTEOBLASTO}

Recentemente, evidências experimentais mostraram que o defeito ósseo visto no XLHR pode ser indepen- 
dente do defeito renal, existindo talvez uma disfunção associada intrínseca do osteoblasto.

A formação óssea endosteal defeituosa no Hyp não é corrigida pelo tratamento com fosfato, e apenas uma combinação de doses suprafisiológicas de calcitriol e fosfato cura a lesão osteomalácica no osso. Esta observação, juntamente com outras, clínicas $\mathfrak{c}$ histológicas, indicam uma função osteoblástica prejudica$\mathrm{da}$, talvez com um papel para um fator intrínseco de osteoblasto dentro do fenótipo clínico.

Osteoblastos e periósteo transplantados de camundongos Hyp em animais normais (20) resultaram em formação de osso anormal, mesmo com fosfato sérico normal, ao contrário de transplantes entre camundongos normais, que se desenvolvem normalmente. Além disso, respostas inapropriadas às doses fisiológicas de calcitriol foram demonstradas em osteoblastos Hyp (21).

Ao contrário do rim, onde há um defeito no transporte de fosfato, os osteoblastos Hyp não têm nenhuma alteração no transporte tanto normal como estimulado de fosfato (21).

Rifas et al. (22) demonstraram no modelo Hyp, uma subfosforilação da osteopontina (uma proteína de matriz óssea que pode ser fosforilada pela caseínaquinase) associada a uma reduzida atividade da cascína-quinase II do osteoblasto. Outras anormalidades bioquímicas demonstradas no osteoblasto Hyp incluem aumento da gliconeogênese e diminuição do $\mathrm{pH}$ intracelular.

\section{ASPECTOS GENÉTICOS}

\section{Efeito de gênero / Antecipação / Imprinting}

Em uma doença dominante ligada ao X, é esperado um efeito chamado de "dose de gene", quando se observa uma doença mais leve nas mulheres que nos homens. Foi relatado um efeito dose de gene não usual, órgão específico, no XLHR. O efeito foi encontrado em osso e dente, mas não se encontrou nenhuma diferença entre machos e fêmeas na perda renal de fosfato. O fenótipo renal parece ser completamente dominante sem o efeito de dose de gene.

O estudo de Whyte e cols. (23) mostrou não haver nenhuma diferença entre os gêneros na altura $e$ nos parâmetros bioquímicos em crianças com XLHR.

$\mathrm{O}$ mesmo estudo mostrou que não há evidência de efeitos de raça, antecipação ou imprinting na expressão do XLHR nas crianças.

\section{Padrão de inativação do $X$}

Nas células de fềmeas de mamíferos, um dos dois cromossomos $\mathrm{X}$ é inativado. Pensa-se que esta inativação ocorra ao acaso, afetando o cromossomo de origem materna ou paterna. As portadoras de um distúrbio recessivo ligado ao $\mathrm{X}$, portanto, podem, em raras ocasiões, ser afetadas. Em portadoras de distúrbios dominantes ligados ao $\mathrm{X}$, uma maior variação na manifestação é esperada, dependendo do padrão de inativação do X. De fato, portadoras de XLHR já foram descritas como sem nenhuma doença óssea.

A inativação preferencial (não ao acaso), em portadoras de distúrbios ligados ao $\mathrm{X}$ pode ser resultado de uma seleção pós-transcricional contra o cromossomo que contém o alclo mutante ou o do tipo selvagem. Uma explicação sugerida para o fenótipo renal dominante é a inativação preferencial do cromossomo $\mathrm{X}$ que traz o alelo selvagem. Orstavik e col. (24) determinaram o padrão de inativação do $\mathrm{X} \mathrm{em} 13$ pacientes com XLHR e compararam com o padrão de inativação de 30 controles. Não houve uma diferença significativa entre os dois grupos. Porém, a inativação ao acaso do $\mathrm{X}$ nas células do sangue periférico, não exclui a possibilidade de uma inativação preferencial em células do túbulo renal.

\section{Heterogeneidade de locus}

Devoto e col. (25) descreveram uma família com uma tubulopatia ligada ao X levando a uma insuficiência renal progressiva, que difere em muitos aspectos do XLHR. O fenótipo afetado nessa família mostrava hipofosfatemia com perda renal de fosfato, osteomalácia, proteinúria e insuficiência renal. Diferentemente do HYP apresentava também hipercalciúria, elevação de calcitriol e P'TH normal-baixo. A análise de ligação mapeou o gene em Xpl 1, excluindo a região do HYP.

Em 1990, Wrong et al. (26) tinham descrito uma condição conhecida como doença de Dent, que parece semelhante a essa tubulopatia ligada ao X. A doença é caracterizada por distúrbio tubular proximal familiar, proteinúria de baixo peso molecular, hipercalciúria, nefrocalcinose, nefrolitíase e insuficiência renal. Pela análise de ligação, foi demonstrado que o locus gênico para a doença de Dent mapeia também no locus Xpl 1.22. Provavelmente, as duas doenças estão associadas à mesma lesão molecular, ou até ao mesmo gene defeituoso. Essas tubulopatias têm muitas semelhanças bioquímicas com a condição hipofosfatêmica do camundongo Gy.

Recentemente, uma grande família com quatro gerações foi descrita com um fenótipo clínico idêntico ao do XLHR, mas com recombinação dupla em alguns marcadores flanqueando o locus HYP (27). A explicação sugerida foi heterogeneidade de locus. 
As evidências, então, acumulam-se a favor de uma possível heterogeneidade de locus no XLHR, com os estudos em humanos e animais mostrando que a heterogeneidade fenotípica encontrada nas hipofosfatemias ligadas ao $\mathrm{X}$ podem muito bem ser determinadas geneticamente, e não devido a penetrância variável. O desafio é clonar e caracterizar os diferentes genes esclarecendo as relações entre os distintos efeitos fenotípicos observados ao nível clínico.

\section{Estudos de ligação}

A partir da localização do homólogo murino em um estudo comparativo entre cromossomo X humano e de camundongo (28), foi deduzido que o gene XLH poderia estar na porção distal do braço curto do cromossomo X.

Os estudos de genética molecular usando análise de ligação e multilocus, primeiramente, mapearam o gene HYP no braço curto do cromossomo X flanqueado por dois marcadores (DXS4l e DXS43). Thaker e col. (29) estabeleceram que o locus HYP estava $11 \mathrm{cM}$ distal ao DXS41 e $14 \mathrm{cM}$ proximal ao DXS43. Posteriormente, mapas mais refinados conseguiram localizá-lo num intervalo menor: Xp22.1-Xp22.2, entre dois marcadores DXS365 e DXS1052 (30).

Contribuições importantes para o mapeamento dessa região foram dadas pelos estudos de microssatélites que flanqueiam o locus e pelos estudos de ligação para pesquisar genes de outras doenças como a retinosquise e síndrome Coffin Lowry. Os avanços na genética molecular como o uso dos YAC (cromossomo artificial de levedura) contíguos possibilitaram a clonagem posicional, isolando fragmentos cada vez mais específicos.

\section{YAC contíguo / Clonagem posicional}

Usando análise de ligação, refinou-se a localização do gene XLHR de tal modo que se conseguiu que estivesse contido em um único YAC. Econs e col. (31) demonstraram uma forte ligação com dois marcadores genéticos: DXS365 e DXS274. Subseqüentemente, foi clonado todo o material genético entre esses dois marcadores num contínuo de YAC (33).

Rowe (34), através de análise de ligação em 20 famílias de afetados, apresentou um novo mapa genético de alta resolução da região que contém o gene, definindo novos marcadores, Cap32 e Cap29 flanqueadores distais que estreitaram a região que contém o gene até $\sim 300 \mathrm{~kb}$, também localizando o gene HYP em um único YAC.

A vantagem da clonagem posicional é que o conhecimento da função gênica e sua expressão nos tecidos não são necessárias para localizar o gene da doença. Essa abordagem tem sido usada para identificar um número crescente de genes de doença.

Para encontrar um gene usando a abordagem da clonagem posicional, os investigadores primeiramente usam a análise de ligação para determinar a localização cromossômica do gene da doença. Uma vez que os marcadores "flanqueadores" ligados são determinados, um mapa contigo é construído abrangendo toda a região. Contigos são formados por pedaços sobrepostos de DNA clonado em vetores como cosmídeos, Pi ou YAC. Então o DNA é analisado para identificar todos os genes presentes nessa região. Esses genes são testados para mutação nos indivíduos afetados.

\section{$O$ gene PEX}

Em outubro de 1995, o HYP Consortium (34), um conjunto de 29 investigadores em 5 instituições de pesquisa, relatou o isolamento de um gene candidato HYP da região Xp22.1, por clonagem posicional. O gene mostrou ter homologia com uma família de genes de endopeptidases, cujos membros estão envolvidos na degradação ou ativação de vários hormônios peptídicos, incluindo neprisilina (NEP), enzimas conversoras de endotelinas 1 e 2 (ECE) e Antígeno Kell. Devido à homologia e à função do gene, os autores o denominaram PEX (Phosphate-regulating gene with homologies to Endopeptidases on the $X$-chromosome).

Para identificar o PEX, cosmídeos da região do gene foram isolados e usados como sonda em DNA de pacientes com XLHR por Southern Blot. Casualmente, quatro pacientes apresentaram deleções e os mesmos cosmídeos que identificaram o DNA deletado foram usados para uma seleção de cDNA a partir de uma combinação de bibliotecas de cérebro e figado fetais, e músculo adulto.

A família de metaloproteases de zinco, com a qual PEX tem homologia, é caracterizada por uma curta cauda $\mathrm{N}$-terminal, um único domínio transmembrana e uma longa região $\mathrm{C}$-terminal, contendo o domínio catalítico e um motivo ligador de zinco. As endopeptidases neutras conhecidas clivam proteínas no processo de criar uma forma ativa ou inativa. A homologia com as endopeptidases sugere então que PEX altera a função de uma proteína que atua na regulação do transporte de fosfato.

O substrato para PEX ainda não foi identificado, de modo que o papel desta endopeptidase na fisiopatologia do HYP não foi esclarecido.

A região codificadora do PEX já tem sua estrutura completamente estabelecida: 2483 bp em 22 
exons. O gene PEX do camundongo Hyp foi identificado e clonado, mostrando uma grande homologia com o PEX.

Holm e col. (35) investigaram mutações do PEX em 22 pacientes não aparentados, com o fenótipo XLHR. Em 9 pacientes, foram identificadas as seguintes mutaçòes: 3 mutações sem sentido I deleção de 1 pb com mudança no quadro de leitura, 4 mutações com sentido errado e 1 mutação em ponto de splicing, além de um deles apresentar uma translocação 9q22;13ql4. Como os tipos de mutações variam, parece não haver regiões preferenciais para mutações. Embora eles não tenham identificado todo o gene PEX, e algumas mutações possam ter escapado, a não deteç̧ão de mutações em 13 pacientes e uma translocação $t(9 ; 13)$ encontrada $\mathrm{em}$ um paciente foi sugestivo para eles que outros loci podem estar envolvidos no surgimento do fenótipo hipofosfatêmico.

Rowe e col. (36) analisaram 99 famílias de afetados HYP, pesquisando mutações no gene PEX c encontraram deleções, inserções, mutações sem sentido, codons de parada e mutações em pontos de splicing. Em quatro regiões do gene, mutações "sem sentido" puderam ser relacionadas com a função da proteína: uma mutação na região ligadora de zinco que talvez altere a interação substrato-enzima. Um amplo espectro de mutações parece se reunir nas regiões necessárias para a atividade de protease. A análise computadorizada das demais mutações sugeriu modificações na estrutura secundária, glicosilação, fosforilação c estrutura dessa região catalítica.

Francis (37) sequenciou uma região genômica de $243 \mathrm{~kb}$ contendo PEX. Identificando todas as seqüências limites de exon-intron, demonstrou que PEX tem uma organização exônica muito semelhante a neprilisina. Além disso, fez uma análise mutacional extensa em 43 casos de HYP, encontrando mutações sem sentido, mudanças de quadro de leitura, com sentido errado e em pontos de splicing, evidenciando mais uma vez, a relação da doença com mutações com perda de função no PEX. A quantidade de mutações relatadas e algumas que são família-específicas, indicam uma heterogeneidade molecular significante no XLHR.

De certa forma, a identificação do PEX trouxe mais questões que respostas. Marvin Grieff (38) cita duas grandes perguntas que permanecem sem resposta no que diz respeito à deleção do PEX resultar em XLHR: qual é o substrato para essa endopeptidase e como esclarecer essa herança dominante? Ainda observa que pesquisa em torno desse tema se dirige para a definição das regiões $3^{\prime}$ e $5^{\prime}$ do gene PEX, ainda desconhecidas, bem como para a distribuição normal de seu produto nos tecidos.

\section{O FUTURO}

Em pouco mais de 50 anos, nós caminhamos desde os relatos da síndrome do raquitismo hipofosfatêmico, através de sua descrição clínica, passamos pelos estudos fisiopatológicos extensos, que ainda não são conclusivos a respeito dos sítios de anormalidade no metabolismo fosfo-cálcico, e agora com o desenvolvimento crescente da tecnologia da análise de ligação genética iniciamos um outro caminho de explicações da genética molecular para a síndrome.

O conhecimento da estrutura e função do gene PEX fornecerá informações adicionais importantes sobre a regulação da eliminação renal de fosfato, implicando talvez até no esclarecimento de outras doenças.

Um marcador genético para o raquitismo hipofosfatêmico pode ser útil no aconselhamento genético e na abordagem de pacientes com a doença. Existe uma incerteza se hipofosfatemia é um discriminante confiável no screening de famílias. Também já foi relatado que a hipofosfatemia pode não estar aparente nos primeiros meses de vida e que o tratamento tem mais sucesso se iniciado ao nascimento do que quando o raquitismo se torna evidente. Um marcador de DNA também permitiria um diagnóstico prenatal se as famílias afetadas o desejassem.

\section{REFERÊNCIAS}

1. McKusik VA, Mendelian inheritance in man. 7th ed. Battimore: Johns Hopkins University Press, 1986.

2. Burnett C, Dent CE, Harper C, Warland BJ. Vitamin Dresistant rickets. Analysis of twenty-four pedigrees with hereditary and sporadic cases. Am J Med 1964: 36:222-33.

3. Albright F, Butler AM, Bloomberg E. Rickets resistant to vitamin D therapy. Am J Dis Child 1937;54:529-47

4. Winters RW, Graham JB, Williams TF, McFalls VW, Burnett $\mathrm{CH}$. A genetic study of familial hypophosphatemia and vitamin D resistant rickets with a review of the literature. Medicine 1958:37:97.

5. Christiansen JF. Three familial cases of atypical late rickets, Acta Paediatr Scand 1941:28:247-70.

6. Bianchine JW, Stambler AA, Harrison HE. Familial hypophosphatemic rickets showing autossomal dominant inheritance. Birth Defects 1971;7:287-94.

7. Econs M, McEnery P. Autossomal dominant hypophosphatemic rickets/osteomalacia: Clinical characterization of a novel renal phosphate-wasting disorder. J Clin Eendocrinol Metab 1997;82:674-81. 
8. Tieder M. "Idiopathic" hypercalciuria and hereditary hypophosphatemic rickets - two phenotypical expressions of a common genetic defect. N Eng J Med 1987;316:125-9.

9. Slyper A, Shaker JL, Thometz JG, McCormick K. Osteomalacia with hypophosphatemia and hypercalciuria: a possible new variant of osteomalacia. J Pediatr 1995: 127:105-9.

10. Scriver CR, MacDonald W, Reade T, et al. Hypophosphatemic norachtic bones disease: an entity distinct from $X$-linked hypophosphatemia in the renal defect, bone involvement, and inheritance. Am J Med Genet 1977:1:101-17.

11. Dennis WW, Bello-Reuss E, Robinson RR. Response of phosphate transport to parathyroid hormone in segments of rabbit nephron. Am J Physiol 1977:233:F29-F38.

12. Tenenhouse HS, Scriver CR, Mclnnes RR, Glorieux FH. Renal handling of phosphate in vivo and in vitro by the X-linked hypophosphataemic male mouse: evidence for a defect in the brush border membranes. Kidney Int 1978: $14: 236-44$.

13. Kos $\mathrm{CH}$, Tihy F, Econs MJ, Murer $\mathrm{H}$, Lemieux N, Tenenhouse HS. Localization of a renal sodium phosphate cotransporter gene to human chromosome $5 \mathrm{q} 35$. Genomics 1994;19:176-7.

14. Nesbitt T et al. Normal phosphate transport in cells from the S2 e S3 segments of Hyp-mouse proximal renal tubules. Endocrinology 1996;137:943-8.

15. Tenenhouse HS, Yip A, Jones $G$. Increased renal catabolism of 1,25-dihydroxyvitamin D3 in murine $X$ linked hypophosphataemic rickets. J Clin Invest 1988; $81: 461-5$.

16. Hahn CN, Baker E, Laslo P, May BK, Omdahl JL, Sutherland GR. Localization of the human vitamin D3-24hydroxylase gene (CYP24) to chromosome 20q13.2q13.3. Cytogenet Cell Genet 1993;62:192-3

17. Meyer RA Jr., Meyer MH, Gray RW. Parabiosis suggests a humoral factor be involved in X-linked hypophosphatemia in mice. J Bone Miner Res 1989;4:493-500.

18. Nesbitt T, Coffman TM, Griffiths R, Drezner MK. Crosstransplantation of kidneys in normal and Hyp mice: evidence that the Hyp mouse phenotype is unrelated to an intrinsic renal defect. J Clin Invest 1992;89:1453-9.

19. Econs MJ, Drezner MK. Tumor-induced osteomalacia: unveiling a new hormone. $\mathbf{N}$ Engl J Med 1994; 330: 1679-81.

20. Ecarot B, Glorieux FH, Desbarats M, Travers R, Labelie L. Effect of 1,25-dihydroxyvitamin D3 treatment on bone formation by transplanted cells from normal and $X$ linked hypophosphatemic mice. J Bone Min Res $1995 ; 10: 424-31$.

21. Yamamoto T, Ecarot B, Glorieux FH. Abnormal response of osteoblasts from Hyp mice to 1,25-dihydroxyvitamin D3. Bone 1992: 13:209-15.

22. Rifas L, Gupta A, Cheng S-L, et al. Reduced casein kinase II activity is associated with underphosphorylated osteopontin in Hyp/ $\mathrm{Y}$ mice osteoblasts. J Bone Min Res 1996; 11 (suppl1):S253.

23. Whyte MP, Schrank FW, Armamento-Villareal R. X-linked hypophosphatemia: a search for gender, race, anticipation, or parent of origin effects on disease expression in children. JCEM 1996:81(11):4075-80.

24. Orstavik KH, Orstavik RE, Halse J, X-chromosome inactivation patterns in female carriers of X-linked hypophosphatemic rickets. J Med Genet 1996;33:700-3.

25. Devoto $M$, Bolini A, Enia $G$, Zoccali $C$, Romeo $G$. A new form of $X$-linked rickets with hypercalciuria (HPDR-11) maps in the Xpll region. Am J Hum Genet 1993:53:993.

26. Wrong OM, Norden AGW, Feest TG. Dent's disease a Fanconi renal tubular syndrome with hypercalciuria, tubular proteinuria, rickets, nephrocalcinosis and eventual renal failure. Q J Med 1990;77:1086-7.

27. Rowe PSN, Read AP, Mountford R, Benham F, Kruse TA, Camerino $G$, et al. Three DNA markers for hypophosphatemic rickets. Hum Genet 1992;89:539-42.

28. Buckle VJ, Edwards JH, Evans EP, Jonasson JA, Lyon MF, Peters J, et al. Comparative maps of human and mouse X-chromosome. (Abstract) Cytogenet Cell Genet $1985 ; 40: 594-5$

29. Thakker RV, Read AP, Davies KE, Whyte MP, Weksberg R, Glorieux $F$, et al. Bridging markers defining the map position of X-linked hypophosphataemic rickets. J Med Genet 1987;24:756-60

30. Read AP, Thakker RV, Davies KE, Mountford RC, Brenton DF, Davis $M$, et al. Mapping of human X-linked hypophosphataemic rickets by multilocus linkage analysis. Hum Genet 1986:73:267-70.

31. Econs MJ, Fain PR, Norman M, Speer MC, Pericak-Vance $M A$, Becker PA, et al. Flanking markers define the $X$ linked hypophosphatemic rickets gene locus. J Bone Miner Res 1993:8:1149-52.

32. Francis F, Rowe PSN, Econs M, See CG, Benham F, O'Riordan JLH, et al. A YAC contig spanning the hypophosphataemic rickets disease gene conadidate region. Genomics 1994:21:229-37.

33. Rowe PSN, Goulding JN, Francis F, Oudet C, Econs MJ Hanauer $A$, et al. The gene for X-linked hypophosphataemic rickets maps to a $200-300 \mathrm{~kb}$ region in Xp22.1, and is located on a single YAC containing a putative vitamin D response element (VDRE). Hum Genet 1996;97:345-52.

34. HYP Consortium. A gene (PEX) with homologies to endopeptidases is mutated in patients with X-linked hypophosphatemic rickets. Nature Genet 1995; $11: 130-6$.

35. Ingrid Holm, et al. Mutational analysis of the PEX gene in patients with $X$-linked hypophosphateic rickets. Am J Hum Genet 1997:60:790-7.

36. Rowe PS, Goulding JN, Francis F, Oudet C, Econs MJ Hanauer $A$, et al. Distribution of mutations in the PEX gene in families with $X$-linked hypophosphatemic rickets (HYP). Hum Mol Genet 1997:6(4):539-49. 
37. Fiona Francis, et al. Genomic Organization of the human PEX gene mutated in X-linked Dominant Hypophosphatemic Rickets, Genome Res 1997;7(6): 573-85.

38. Marvin Grieff. New insights into X-linked hypophosphatemia. Curr Opin Nephrol Hypert 1997:6:15-9.

\section{Endereço para correspondência:}

Marise Lazaretti-Castro

Disciplina de Endocrinologia, UNiFESP

Rua Pedro de Toledo, 910

Caixa Postal 20266

04034-970 São Paulo, SP 